\title{
La colonización minera y agrícola en la ciudad Imperial del Sur de Chile: 1551-1561
}

\author{
Iván InOSTROZA CoRDOva \\ Universidad de la Frontera, Temuco, Chile \\ luis.inostroza@ufro.cl
}

Recepción: 1 de octubre de 2012 / Revisión: 30 de noviembre de 2012

Aceptación: 20 de diciembre de 2012 / Publicación: diciembre de 2013

\begin{abstract}
Resumen
Estudio de la organización económica en el corregimiento de la ciudad Imperial establecida desde 1551 en el Sur de Chile. Se analizan las características de la colonización hispana en torno a la producción minera de oro, la producción agrícola de trigo, el tráfico mercantil en su conexión con el puerto de Valdivia y el volumen de la población laboral indígena, en la etapa inicial del asentamiento español en la comarca de los ríos Cautín y Toltén.
\end{abstract}

Palabras clave: conquista, ciudad Imperial, economía colonial, minería, agricultura, demografía indígena Chile, siglo XVI.

\section{Mining and Agricultural Colonization in the Imperial City of Southern Chile: $1551-1561$}

\begin{abstract}
Study of the economic organization of the Imperial city district established since 1551 in southern Chile. We analyze the characteristics of the Spanish colonization around gold mining production, agricultural production of wheat, commercial traffic in connection with the port of Valdivia and the volume of the indigenous workforce, in the initial stage of the Spanish settlement in the region of rivers and Toltén Cautín.
\end{abstract}

Key words: Conquest, Imperial City, Colonial Economy, Mining, Agriculture, Indian Demography, Chile, $16^{\text {th }}$ Century.

Sumario: 1. Introducción. 2. Arquitectura fortificada de la ciudad Imperial. 3. La minería del oro. 4. La producción agroganadera. 5. Comercio, tráfico terrestre y marítimo intercolonial. 6. La población indígena del corregimiento. 7. Conclusiones. 8. Referencias bibliográficas. 


\section{INTRODUCCIÓN ${ }^{1}$}

Después de la conquista del Perú los españoles exploraron las provincias meridionales del Tahuantinsuyo, arribando en forma exploratoria a la región de Chile en 1535, para asentarse definitivamente desde 1541 con la fundación de Santiago y La Serena en 1544; Concepción en 1550, Imperial en1551, Valdivia en 1552; Villarrica y Angol en 1553, Osorno en 1558 y, finalmente, Castro en 1567 en la isla de Chiloé ${ }^{2}$. La fundación de ciudades conformó el mecanismo más decisivo en el éxito de la empresa conquistadora en el continente descubierto ${ }^{3}$. Su función era vital en los territorios de guerra amenazados por la resistencia indígena para mantener los pertrechos bélicos y la seguridad de la hueste, resguardar a los futuros vecinos y organizar la vida económica del corregimiento. Por otro lado, la economía articulada desde las ciudades en el territorio conquistado, tanto en Chile central como en la zona Sur, se caracterizará por una combinación de actividades mineras auríferas con producción agrícola y ganadera en haciendas y estancias desde los inicios del asentamiento español, contribuyendo al desarrollo de un distrito colonial muy dinámico durante el siglo XVI.

\section{ARQUITECTURA FORTIFICADA DE LA CIUDAD IMPERIAL}

El avance de la conquista española hacia el Sur de Chile se inició a fines de 1549 con la marcha de Pedro de Valdivia hacia la desembocadura del río Biobío. En la bahía de Penco fundará la ciudad de Concepción en octubre de 1550, como enclave portuario destinado a sostener la conquista de Arauco a Chiloé. En enero de 1551 los españoles se dirigen más al Sur a la comarca del río Cautín, ingresando por la costa hacia el interior del continente para construir en la confluencia con el río Damas un asiento fortificado en marzo de 1551, a unos 30 kilómetros del mar, alrededor del cual se delineara la traza de la ciudad Imperial en enero de $1552^{4}$. El lugar elegido contaba con una excelente disposición topográfica para su defensa frente a los ataques indígenas en una colina de mediana altura defendida al Sur y Oeste por el profundo estuario del río Cautín, mientras su ladera Norte caía hacia un estrecho valle junto al río Damas, en cuya ribera septentrional se alzaban algunos cerros, formando un cañadón de fácil defensa. Su posición ribereña facilitaría, además, una eventual evacuación hacia la costa, así como recibir pertrechos desde otros puntos de la Gobernación de Chile y el Perú.

\footnotetext{
1 El autor agradece el auspicio de esta investigación a la Comisión Nacional Científica y Tecnológica y del Fondo Científico y Tecnológico de Chile en el marco del Proyecto FONDECYT 19991990252 "La economía regional de Concepción y su articulación al circuito comercial de Lima 1620-1680".

2 Guarda, 1978, 1990, 1993; Campos Harriet, 1979; Villalobos, 1983; Martinic, 1983; Muñoz Correa 1989, 1992; LeÓn, 1991; Barros, 1991-1992; CÁCeres 1991; De Ramón, 2000.

3 Solano, 1996, pp. 615-636, propone el concepto de "conquista urbana" para esta estrategia.

4 Carta de Pedro de Valdivia al Príncipe don Felipe. Concepción, 20-X-1552. En Colección de documentos inéditos relativos a la historia nacional (En adelante CDIHCh), Santiago, 1900-1903, tomo 9, p. 442.
} 
Mapa 1: Distrito de la Imperial, 1551-1571

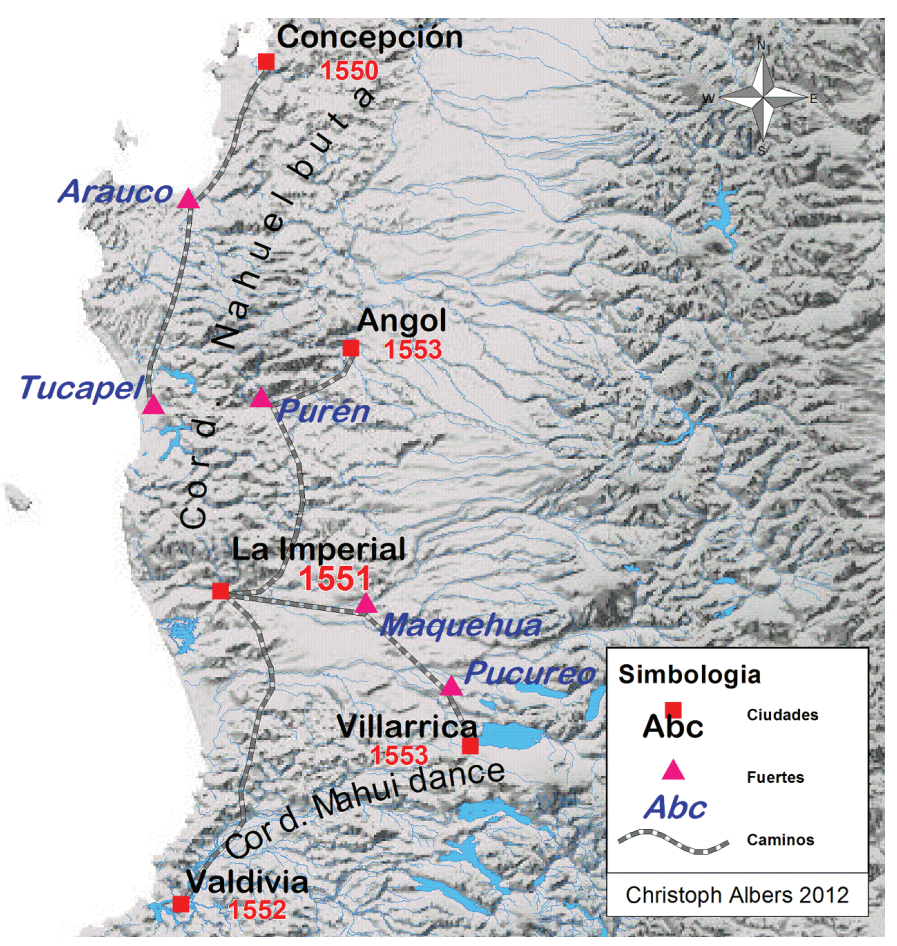

Elaborado por Cristoph Albers

Jerónimo de Bibar, cronista de la expedición, apuntaba respecto de la instalación de los españoles en el río Cautín:

Como el gobernador hallase tan buen sitio y en tan buena comarca y tan apacible, y que allí podía pagar a los conquistadores su trabajo y dalles muy bien de comer, fundó allí una ciudad e intitúlala la Imperial. Pasa por ella el río Cautén, hondo y muy poderoso. Pasa otro pequeño río por un lado de la ciudad. Luego puso por obra de hacer un fuerte encima de la loma donde había de ser la ciudad, en que dejase la gente que le pareciese para volverse con 15 o 20 hombres a la ciudad de la Concepción. Luego se entendió en hacer una cava y casas y en recoger comida para que quedasen apercibidos y que no les faltase. Esta es una loma que está sobre el río de Cautén. Es tierra doblada y en partes llana. Es tierra muy poblada. Tiene el monte legua y media de donde se trae la madera para las casas ${ }^{5}$.

Estas favorables condiciones defensivas fueron aumentadas con la construcción de un fuerte en diez o doce días, como informaba Pedro de Valdivia ${ }^{6}$. La fortaleza fue edificada por Pedro de Villagrán, cabo de la guarnición y primer corregidor de la

\footnotetext{
5 BiBAR, 1966, p. 150.

6 Carta de Pedro de Valdivia al rey de España. Concepción, 25-IX-1551. CDIHCh, tomo 9, p. 400.
} 
ciudad, utilizando material pétreo para las murallas. Un soldado español confirmaba su factura extraordinaria, señalando que Villagrán: "hizo un fuerte muy fortalecido en que se recogieron los españoles, e después comenzó a traer la tierra e naturales en paz" gena en el transporte de los materiales, debido a la falta de animales de carga como bueyes y mulas en los primeros años del avance ${ }^{8}$. Un vecino señaló más tarde, que las tareas impuestas a los indígenas de la comarca fue: "causa de que muy grande cantidad de naturales pereciesen, así por los que llevaban con cargas, como por comelles las comidas"9.

El uso de la piedra en las edificaciones de las ciudades de la conquista fue de dominio universal, en consideración a su eficacia defensiva y también para cumplir con disposiciones legales que reflejaban la orientación señorial de esta nueva nobleza urbana, de conquistadores americanos. Su amplia difusión como material de la arquitectura española, también fue un elemento indicativo del progreso urbanístico y económico. En esta perspectiva, en una probanza de méritos y servicios se estipulaba que: "el dicho Antonio Tarabajano tuvo mas de 3.000 indios en la ciudad Imperial mas de cinco años, donde fue vecino, alcalde e regidor e tuvo chácaras, e hizo la casa de piedra" ${ }^{10}$. La piedra evitaba los siniestros que afectaban a las edificaciones de madera, sobre todo por la amenaza de incendios que afectaron a la aldea ${ }^{11}$.

Después de la derrota y muerte de Pedro de Valdivia a fines de 1553 en la batalla de Tucapel, distrito de Concepción, rebrotó la resistencia indígena y la naciente ciudad Imperial fue protegida en sus accesos urbanos con "cercada de palizadas y fosos"12; para servir de refugio a los vecinos españoles de los asentamientos de Angol y Villarrica, fundados en el interior de Araucanía. El repliegue de los efectivos hispanos fortaleció el contingente militar facilitando una cruenta represión en la comarca del río Cautín, destinada a eliminar la resistencia local imponiendo un férreo control para impulsar el desarrollo de la colonización en el corregimiento.

Respecto del número de vecinos de la ciudad el cabildo de Imperial envío al rey en septiembre de 1552 una descripción del emplazamiento de la ciudad, señalando un número de: "cuasi ochenta vecinos, capitanes y conquistadores de esta tierra" ${ }^{13}$. El cronista Diego de Rosales, apuntaba sobre la distribución de los solares para edificios en torno de la plaza indicando detalles de la arquitectura pétrea de sus construcciones urbanas:

\footnotetext{
7 Información de servicios de Pedro de Villagrán. Concepción, 11-IX-1562. CDIHCh, tomo 13, p. 306.

8 Información de méritos y servicios de Miguel de Velasco y Avendaño. Ciudad de los Confines (Chile), 28-IX-1563. CDIHCh, tomo 10, p. 12.

9 Información hecha por el fiscal Juan Pérez Teruel para acreditar los delitos y agravios que Francisco de Villagra hizo en esta gobernación, especialmente después que murió don Pedro de Valdivia, Gobernador que fue de ella. Concepción, 12-XI-1558. CDIHCh, tomo 20, p. 385.

10 Probanzas de Juan Gómez Almagro y Antonio Tarabajano. Santiago, 14-VIII-1561. CDIHCh, tomo 11, p. 51 y 71 .

11 Proceso de Villagra III. Actuaciones hechas en la ciudad de Valdivia. Declaración de Juan Bautista Pastene. Valdivia, 20-IX-1558. CDIHCh, tomo 22, p. 452.

12 Probanzas de Juan Gómez Almagro y Antonio Tarabajano en el pleito seguido entre ambos sobre la encomienda de indios de Topocalma. Santiago, 14-VIII-1561. CDIHCh, tomo 11, p. 71.

13 Carta al rey de la Justicia y Regimiento de la Imperial sobre su fundación. Imperial, 20-IX-1552. CDIHCh, tomo 9, p. 438.
} 
y aunque al principio la Yglesia Parroquial, que se hizo, y las casas fueron de paja, después por una quema que hubo, y porque cada uno, como tenía tanta multitud de indios, quiso perfeccionar su casa, se hicieron de piedra las más, por haber allí unas lajas muy al propósito, y otras de adobe, o tapias, y las cubrieron de teja, con muy buena enmaderación, y tablería ${ }^{14}$.

El cronista Miguel de Olivares, siguiendo los registros de la ciudad Imperial escribió detalles bien precisos sobre los edificios públicos y primeros integrantes del cabildo:

El Gobernador señaló en la nueva ciudad, un flanco de la plaza para iglesia y casas episcopales, otra para casas de ayuntamiento y cárceles, y las dos restantes para habitación de los fundadores distinguidos. Dedicó solar para erecciones de una capilla a honra de nuestra señora de la Antigua, y otro más capaz para otra capilla dedicada al misterio de la Inmaculada Concepción, y después continuó la distribución de solares en todos los pobladores. Nombró alcaldes Francisco Villagra y Gaspar Orense; regidores Juan de Vera. Gaspar de Castañeda, Leonardo Cortés, Fernando de Mares. De los demás vecinos quedan mencionados en algunos manuscritos, los siguientes: Pedro de Olmos de Aguilera, don Miguel de Velasco, Francisco Gutiérrez, Andrés Martínez, Diego Martín Ballesteros, Gabriel de Pevilla, Antonio Saldaña, Juan Hidalgo, Antonio Cervera, Alonso de Miranda, Baltasar Rodríguez, Juan de Ocampo, Hernando de San Martín, don Luis Barba, Juan de Ceballos y Andrés Montesinos ${ }^{15}$.

La planta urbana adaptada a la topografía habría tenido una disposición triangular con vértices de cinco cuadras paralelas al río Cautín y otras cinco cuadras de fondo ${ }^{16}$. Junto a los solares urbanos los vecinos recibieron chacras en el valle aledaño del río Damas, como se indica en el documento de permuta de bienes entre Juan Gómez vecino de la ciudad de Santiago y Gaspar Orense, vecino de la Imperial:

doy a voz el dicho Juan Gómez las casas e solares que yo tengo en la dicha ciudad Imperial, que alindan de la una parte con casas y solares del capitán Julián Samano, y de la otra parte casas e solar de Juan Jiménez, calle en medio; y de la otra parte, la caída del río las Damas, e por la otra parte la caída del río Cautén, e asimesmo la chácara que yo tengo en el termino de la dicha ciudad Imperial, que alindan de la una parte con chácara que solía ser de Jerónimo de Alderete, y por la otra parte alindan con el río de las Damas, segund que por los títulos que dellos tengo parecerá ${ }^{17}$.

Respecto del distrito y términos del corregimiento se apuntaba hacia 1570, cuando se había establecido la sede del Obispado de la Imperial en la ciudad:

\footnotetext{
14 Rosales, 1989, tomo I, p. 402. En virtud de la escasez de fuentes directas del siglo XVI, utilizamos los testimonios recopilados por cronistas posteriores que consignan descripciones de las ruinas urbanas y referencias copiadas de archivos y documentos de la ciudad Imperial del siglo XVI.

15 Olivares, 1864, p. 129.

16 Guarda, 1978, p. 39.

17 Probanzas de Juan Gómez Almagro y Antonio Tarabajano. Santiago, 14-VIII-1561. CDIHCh, tomo 11, p. 176.
} 
Desde la ciudad de los Confines, hasta la Imperial, va el camino al Oeste Sudueste, esta la Imperial cuatro leguas del mar, un río arriba que llaman Vten [Cautén], que baja de la sierra nevada del Leste: pasa junto a la Ciudad Sur de ella, y otro mas pequeño por la parte del Oeste, y queda la ciudad en una punta entre los dos ríos, en una loma bien alta, y de áspera subida; esta en 38 grados, y 50 minutos. Esta ciudad es cabeza del segundo Obispado del Reino de Chile, sus términos comienzan a diez leguas a su Norte, y acaban por la parte del Sur en Queule, que es un río deste nombre, hasta el cual hay desde la ciudad 18 leguas, y esta en 39 grados y medio, por lo cual parece tener de termino Norte Sur, 18 leguas, y al Leste Oeste 20 leguas, que hay desde la Mar a la Sierra Nevada ${ }^{18}$.

Los términos de 18 leguas de Norte a Sur y 20 del mar a la Cordillera de los Andes, incluyen el territorio de las hoyas hidrográficas de los ríos Tirúa, Chochol, Cautín, Toltén y Queule.

\section{LA MINERÍA DEL ORO}

La economía del siglo XVI se caracteriza por la intensiva explotación de los minerales de oro en el territorio de Copiapó a Chiloé. Según la versión historiográfica tradicional las explotaciones mineras españolas no contarían con antecedentes prehispánicos, o a lo menos de importancia entre las comunidades mapuche. Sin embargo, el estudio de las fuentes documentales ha revelado que los indígenas del Sur de Chile utilizaban profusamente joyas de oro, plata y cobre, y daban usos bélicos y productivos a instrumentos fabricados de materiales cupríferos. La explotación minera y el trabajo de los metales se extendían a través de todo el país mapuche-huilliche del siglo XVI, situación que incentiva la progresiva expansión europea desde Concepción a Chiloé. Jerónimo de Bibar en 1550 describe el uso de joyas confeccionadas con los metales señalados, en los distritos de Concepción e Imperial, indicando que las mujeres:

Traen "brazaletes de oro y de plata y una manera de coronas". Traen al pescuezo una manera de diadema y de turquesas y de "tiritas de oro" a manera de estampas. Ellas andan como las del Mapocho, salvo que traen una manera de "zarcillos de cobre"19.

El uso de estos metales preciosos en la sociedad mapuche precolombina también cuenta con registros arqueológicos. Aros de cobre, plata y oro tienen fechados desde el año 1000 d.C. con influencia cuzqueña y del Nor-Oeste argentino. También se han reconocido instalaciones mineras prehispánicas, en la zona baja del río Cautín y en la zona superior del río Toltén, lugares donde se fundaron las ciudades de La Imperial y la Villa Rica para explotar los yacimientos existentes ${ }^{20}$.

La explotación minera comenzó con gran intensidad en los asientos auríferos diseminados en el distrito $^{21}$. En 1553 los oficiales reales escribían que la actividad ex-

18 Herrera, 1730 , p. 157.

19 Bibar, 1558, p. 180; InOSTROZA, 2010.

20 Dillehay, 2011, p.150; Campbel, 2008; AdÁn - Mera, 2010.

21 Interrogatorio de los servicios de Leonardo Cortés. Imperial, 15-XI-1577. CDIHCh, tomo 19, p. 475. 
tractiva había permitido acopiar remesas de oro provenientes del impuesto del quinto real, y que pronto enviarían a España los caudales procedentes del tributo minero ${ }^{22}$. El avance de la colonización sólo era posible en el marco de la sujeción militar de los indígenas y su posterior reparto en encomiendas, entre los conquistadores españoles de mayor renombre en la conquista de Chile como informaba el licenciado Santillán en 1557:

en aquella sazón los vecinos de la dicha ciudad se servían de los dichos indios e les daban a unos de 6 e a otros de 7.000 e a otros de mas e a otros de menos, y estos los ocupaban algunos de ellos en hacer sementeras, e otros en casas y en sacar oro de las minas, el cual oro se sacaba 40 días antes que le matasen al dicho Pedro de Valdivia ${ }^{23}$.

La riqueza aurífera de la comarca del río Cautén incentivó el enganche de soldados y la migración de vecinos encomenderos desde el corregimiento de Santiago al distrito de Imperial, con la perspectiva de una rápida y abundante riqueza. En una información sumaria de permuta de bienes entre el vecino Gaspar de Orense y Juan Gómez encomendero de la ciudad de Santiago, se indicaba que éste último había recibido y: "tenía 4 a 5.000 indios, e sabe que son cuatro leguas de esta ciudad, e que tienen muchas tierras de buena labranza en crianza" ${ }^{24}$. Otro testimonio recogido en esta información señalaba que el trabajo de los indígenas en las minas había generado ingentes riquezas a Gómez:

le dieron mas de 50.000 pesos de oro que le sacaron de las minas, como parece de la dicha visita y del libro de la fundación; e que lo demás que la pregunta dice es público e notorio el haber tenido indios el dicho Juan Gómez en la ciudad de la Imperial que son los que la pregunta dice, y que eran muy buena cosa los dichos indios de Tabón, por estar cerca de la ciudad Imperial e ser cantidad de indios ${ }^{25}$.

La referencia al registro en el "libro de la fundación", corrobora la veracidad de las cifras apuntadas, ilustrando una importante fortuna individual recolectada anualmente.

La explotación del oro contribuyó poderosamente a sentar las bases de la dominación colonial. Diego de Rosales, esboza un corolario de la fama gozada por el oro de Imperial en los primeros años de la conquista del río Cautín, escribiendo:

22 Carta de Jerónimo de Alderete y Vicencio de Monte al Emperador dando cuenta de lo que iba ejecutando P. de Valdivia en la conquista de Chile, s.1. 25-IX-1551. CDIHCh, tomo 9, pp. 405-406. Alderete escribe este apartado como tesorero de la Real Hacienda como consta en CDIHCh, tomo 9, p. 448.

23 Información levantada en Concepción ante el Licenciado Hernando de Santillán, en 1557, acerca de la conducta de Villagra después de la muerte de Pedro de Valdivia. Concepción, 9-X-1559. CDIHCh, tomo 20, p.12.

24 Probanzas de Juan Gómez Almagro y Antonio Tarabajano. Santiago, 14-VIII-1561. CDIHCh, tomo 11, p. 153.

25 Probanza de don Francisco Irarrázaval en la causa seguida a su instancia contra Juan Gómez y el fiscal de Su Majestad, sobre la tenencia de ciertos indios del valle de Quillota en las provincias de Chile. Los Reyes, 1-XII-1565. CDIHCh, tomo 23, p. 69. 
Las minas de aquella tierra, fueron muchas, y muy ricas, porque en los cerros, por donde baja el río de las Damas, las había abundantísima; y en las lomas de Calcoimo y Relomo, fueron más célebres, por ser el oro allí más crecido y de mayores pepitas, o granos. Por donde entra el río de Repocura al río de La Imperial, se sacaba muchísimo oro $^{26}$.

El beneficio de los primeros años de explotación fue de tal magnitud, que Pedro de Valdivia envío a España a su lugarteniente Jerónimo de Alderete con grandes muestras del mineral áureo, y previsiblemente también de plata, marcando un parangón con las remesas enviadas por Pizarro con el tesoro de Atahualpa. En marzo de 1554 Alderete se encontraba en la Corte con el deslumbrante tesoro de Arauco ${ }^{27}$, obteniendo para las fundaciones de Imperial y Valdivia el título de ciudad y privilegio de armas por reales cédulas de ese año.

Como síntesis de las características de la producción de oro en el siglo XVI, señalaremos algunas cifras generales. En 1560 Juan de Hinojosa declaraba que el gobernador García Hurtado arribado en 1557, puso diligencia para descubrir y explotar minas de oro durante su gobierno: "porque en un navío solo dicen que vinieron 400 o 500.000 pesos" 28 . El cronista López de Velasco en 1572, entregaba una cifra global de la producción aurífera en la gobernación de Chile en el período 1542-1560: "por haber estado siempre la tierra de guerra, se sacaron desde el año 42 hasta el de 60 más de 7.000.000 de oro suelto" 29 . No obstante la referencia a la permanencia de un clima bélico y de inestabilidad de la ocupación hispana, la cifra de 7.000.000 de pesos de oro representa una enorme riqueza para la época. Los historiadores Mario Góngora y Armando de Ramón, siguiendo los registros del quinto real destacan el gran volumen de la producción aurífera en la gobernación Chile, relevando a Chile como una de las regiones americana de mayor producción en el siglo $\mathrm{XVI}^{30}$. El profesor Sergio Villalobos matiza esta cifra planteando que se trata de una "enormidad", por tratarse de sumas, a su juicio, "desconcertantes" 31 ; sin embargo, acepta los testimonios estadísticos basados en la recaudación del quinto real que evidencia altos rendimientos extractivos con una recaudación anual superior a 40.000 pesos de oro.

El cronista Rosales, releva la importancia de la minería en el distrito del Cautín señalando que durante el siglo XVI:

el peso de oro valía en Chile siendo de perfecta ley 450 maravedís, como consta de los libros de rentas de la Iglesia Catedral de la Imperial (...) de los libros de cuentas

26 Rosales, 1989, tomo I, p. 400. Villalobos observa que las cifras entregadas por Rosales son de utilidad porque recogió información de los libros de contabilidad del obispado de Imperial. ViLlaLOBOS, 1983, tomo 2 , nota 13 .

27 Porras Barrenechea, 1999, p. 210 y ss.; Barros, 1873, p. 340.

28 Probanza de los méritos y servicios de don García de Mendoza y Manrique. Los Reyes, 7-V-1561. CDIHCh, tomo 27, p. 212.

29 LÓpez de Velasco, 1894, p. 517. Una mirada global de la información sobre la colonización española en América consignada por López de Velasco en Slicher VAn BAt, 1979; Cuesta, 2007.

30 Góngora, 1970; De RAmón, 2000, pp. 34-35.

31 Villalobos, 1983, tomo 2, p.15. El profesor Villalobos realiza una meritoria cuantificación de la producción aurífera en los lavaderos del Sur, aportando una serie de pistas documentales que utilizamos en este artículo. Otros antecedentes generales en MiLlán, 2001. 
de sus mayordomos, consta, que la tarea de cada día era, de 700 pesos de oro, y a esta proporción le acudían de otros minerales ${ }^{32}$.

Los indígenas sacaban rendimientos de 700 pesos de oro diario, que representaría una producción de 150.000 pesos al año, cifra indicativa de los deslumbrantes caudales reunidos por los españoles en las primeras décadas de su instalación en la Imperial. Esta riqueza contribuiría al progreso y magnificencia de la urbe y sus edificios, como apuntaba un cronista:

La devoción de los pobladores se dio bien a conocer en la atención de las casas de culto divino, que se infiere del crecido número de alhajas preciosas que halló en los templos y capillas de su jurisdicción episcopal el doctor frai Antonio de San Miguel en la primera visita que de ella hizo en 1574, y consta de un protocolo eclesiástico que se guarda en el archivo de la ciudad de Concepción ${ }^{33}$.

Gabriel Guarda señala que los vestigios arqueológicos de los basamentos de los edificios de la ciudad, corroboraban la imponencia urbanística de las ruinas de la Catedral, del Convento de la Merced y del Convento de San Francisco. Asimismo, la fundación del Convento de Santa Clara con religiosas traídas directamente desde la ciudad del Cuzco, contribuían a realzar el desarrollo económico alcanzado en la Imperial $^{34}$.

Los datos disponibles hasta ahora, han influido en el enfoque historiográfico acerca de la decadencia de los lavaderos de oro desde 1580. No obstante, Villalobos, advierte que este colapso estuvo lejos de ser total. Principalmente porque el agotamiento de los placeres aluviales derivado de la intensa explotación durante los primeros años, dio lugar a fines de la década de 1570 a nuevos descubrimientos de minas de oro y, sobre todo, de minas de plata. Sobre los nuevos descubrimientos argentíferos, se informaba al Rey en 1579 desde la ciudad de Angol:

Viendo que no se podía hacer efecto y que entraba el invierno quise aprovechar el tiempo y teniendo de muchos años atrás noticias de metales de plata hacia la cordillera nevada, con guías caminé a un cerro donde se descubrió una cueva labrada en el cerro de grandes vetas de metal y por no tener hombre que conociese de ello mandé cargar dos caballos de metal y se ha traído a esta ciudad donde se ha sacado la plata (...) No me detuve más que sólo un día en aquella parte por cargar el invierno tan recio, aunque los indios tres leguas más adelante en la propia cordillera me certifican haber muchas mas cantidad de metal y plata muy fina ${ }^{35}$.

\footnotetext{
32 Rosales, 1989, tomo I, p. 187.

33 Olivares 1864, p. 130.

34 GuARDA, 1978, p. 40; también encontramos migrantes cuzqueños en Imperial como plateros. Sobre las migraciones de indígenas peruanos en el siglo XVI ver VALENZUELA 2010.

35 Carta de Lorenzo Bernal del Mercado al rey sobre el estado del reino. Los Confines de Angol, 15-VI1579. CDIHCh $2^{\text {a }}$ serie, tomo 2, p. 442.
} 
Respecto de la minería del oro, en el mismo documento se indicaba:

En la ciudad Imperial se ha descubierto minas de oro muy ricas en tanta cantidad de tierra que no se podrán acabar, hanse labrado aunque mal y con sobresalto por estar cercanas a la tierra de guerra, habranse sacado para muestra 70.000 pesos sin haber cuadrillas formadas sino de indios aventureros, es cosa muy rica y sobre todo lo es la plata en tanta cantidad que no tengo duda ninguna sino que consiguiéndose la paz y V.E. envíe persona que lo mueva todo, los navíos irán lastrados de plata y oro ${ }^{36}$.

Esta referencia ilustra el progresivo avance de la actividad extractiva hacia 1580 , basada en el continuo impulso brindado por los descubrimientos mineros en el distrito, ponderando la riqueza obtenida en su explotación. En esta perspectiva en otro documento se apuntaba que en estos años: "se han descubierto muy ricas minas que hogaño con gran dificultad por las guerras que allá he tenido todavía sacaron más de 60.000 pesos, sin lo que los indios hurtaron" ${ }^{37}$. Asimismo, los informes oficiales confirmaban la importancia de estos descubrimientos indicando: "Hanse descubierto minas de plata ahora, dicen ser buenas, lo mismo de oro en la Imperial han sacado 100.000 pesos y más en dos meses a lo que dicen" ${ }^{\text {"38 }}$. Los descubrimientos auríferos de esta década motivaron que desde las ciudades circunvecinas se enviaran mineros indígenas para beneficiar los placeres, remitiendo

indios lavadores para que sacasen oro en La Imperial (...) y sacasen oro todos juntos en las minas que dijo de La Imperial y para esto todos tres pueblos juntaron 3.000 lavadores y los enviaron a las dichas minas y el maese de campo vino a la ciudad Imperial con 80 soldados $^{39}$.

Estos informes confirman claramente que hacia 1580 se inicia una segunda fase de la actividad minera española, previsiblemente también asociada al laboreo de socavones y minas subterráneas.

\section{LA PRODUCCIÓN AGROGANADERA}

La organización de la producción agrícola y ganadera se verificó junto con la explotación del oro, para el avituallamiento vital de productos básicos alimenticios de las ciudades, las compañías de soldados y la masa laboral indígena, conformando una economía colonial de impronta agrícola y ganadera junto a las actividades mineras ${ }^{40}$.

\footnotetext{
36 Ibídem, p. 444.

37 Carta de Martín Ruiz de Gamboa al virrey del Perú sobre la guerra de Arauco. Santiago, 1-IV-1579. CDIHCh $2^{\text {a }}$ Serie, tomo 2, pp. 394-395.

38 Carta de Juan de Villalobos a Francisco de Toledo, virrey del Perú, en que relata los sucesos de la guerra de Arauco, informa sobre Drake y lamenta la falta de premios que ha tenido. Santiago, 18-VI-1579. CDIHCh $2^{\text {a }}$ Serie, tomo 2, p. 451.

39 Carta de Lorenzo Bernal de Mercado al virrey del Perú sobre la guerra de Chile. Santiago, 15-IV-1580. CDIHCh $2^{\text {a }}$ Serie, tomo 3, pp. 42-43.

40 Góngora, 1970; Muñoz Correa, 1992; Inostroza 1992 y 1998.
} 
En el título de encomienda de Jerónimo de Alderete se entregaban predios de labranza para chacra, estancia y haciendas en las tierras de los indígenas encomendados:

y en la tierra de estos principales se os han de dar chacras y caballerías y tierras de pan llevar para la sustentación de vuestra casa, e conforme al gasto que tenéis en ella por cuanto no hay tantas tierras en la ciudad Imperial para dar a los vecinos della, y a esta causa se ha de repartir el daño entre los indios más cercanos ${ }^{41}$.

Los documentos de la permuta entre Gaspar de Orense y Juan de Gómez -ya citados- ofrecen antecedentes sobre el desarrollo de la economía agroganadera implementada por los vecinos del corregimiento de Imperial. En este registro se apuntaba que Orense entregaba a Gómez:

todas las sementeras de trigo e cebada, e frisoles, lino mare y papas e todas las demás semillas que yo tuviere, e mis anaconas, ansi en las dichas chácaras, como en los pueblos, caciques e indios que por repartimiento y encomienda que tengo, ecepto la parte de la sementera que le pertenece a Luis Ternero de solamente el lebo de $\mathrm{Cu}$ llimallen e loma de Imperial, segund se contiene en la escriptura que sobre ello pasó entre mi y Luis Ternero; e asimesmo vos doy toda la madera que yo tengo e entre por $\mathrm{mi}$, ansi en las dichas casas-solares como en los dichos mis pueblos, y todas las bateas que yo tengo fechas en mis pueblos e casas o donde estuvieren en la dicha ciudad Imperial ${ }^{42}$.

Es importante destacar la diversidad productiva de los encomenderos. Particularmente el cultivo de plantas europeas como el trigo, la cebada y el lino destinado a manufacturas textiles, junto a plantas prehispánicas como porotos, maíz, papas y madi; recursos que los hispanos utilizaban a su favor ${ }^{43}$. También es posible advertir la relevancia de la producción maderera, esenciales para las construcciones residenciales. Del mismo modo, las bateas representaban el instrumento típico para el trabajo indígena en los lavaderos de oro y una fórmula de organización laboral minera compuesta de cinco indígenas ${ }^{44}$.

En este marco productivo, en la ciudad Imperial se construyeron grandes y amplias casas que cumplían funciones residenciales y de bodegas, así como talleres fabriles de tenerías de cuero, molinos de harina, e hilanderías de lino utilizando la materia prima de los cultivos de linaza. Sobre la existencia de estas bodegas de productos agrícolas en la ciudad, en los documentos de 1553 se indicaba que con el trabajo en las encomiendas y tierras indígenas se realizaron grandes acopios de granos, y que Francisco de Villagra llegando desde Santiago: "en esta ciudad puso orden e fizo e ordenó hacer un depósito para que los soldados que estaban en ella se sustentasen, e

\footnotetext{
41 Juan Godinez, vecino de Chile, con doña Esperanza de Rueda y Pedro de Miranda, de la misma vecindad, sobre ciertos indios. Valdivia, 4-III-1552. CDIHCh, tomo 14, p. 222-223.

42 Probanzas de Juan Gómez Almagro y Antonio Tarabajano. Santiago, 14-VIII-1561. CDIHCh, tomo 11, p. 176.

43 Bengoa, 2003; Inostroza, 2010; Dillehay, 2011.

44 GÓNGORA, 1970, p. 16.
} 
proveyó lo que cerca de esto convenía" ${ }^{45}$. En otras referencias se consignaba que el Gobernador había entregado 200 cargas de trigo para la manutención de la ciudad ${ }^{46}$. Adicionalmente se remitieron ese año 400 cargas de trigo a la ciudad de Angol $^{47}$. Mientras otro testigo añadía que Villagra envío: "2.000 fanegas de comida desde la isla de su repartimiento, y que así lo hizo siempre"48. Finalmente se concluía que: "en los meses del hambre", Francisco de Villagra: había repartido 18.000 fanegas de $\operatorname{comidas}^{49}$. En esta misma línea se estipulaba:

que asimesmo hubo gran necesidad de comida entre los españoles, que valía una fanega de trigo a tres pesos y medio, porque este testigo lo compró a este precio; e que vio que el dicho mariscal socorría a muchas personas que tenían necesidad, porque decían había repartido veinte mile fanegas de todas comidas, porque este testigo lo oyó decir así a sus criados y a los diezmeros oyó decir que había diezmado al pie de veinte mile fanegas de toda comida ${ }^{50}$.

Estas cifras de 18.000 y 20.000 fanegas de toda comida -generalmente trigo y maíz-, revelan una producción de gran escala que no sólo estaba destinada al sustento de los españoles, también estaba orientada hacia el abasto de las poblaciones indígenas.

El valor del remate de los diezmos para recaudar el tributo de la décima parte de la producción agrícola y ganadera, muestra la importancia de las actividades agropecuarias en el distrito. En el corregimiento de Imperial durante 1552-1558 su valor fue de 25.485 pesos $^{51}$, con un promedio de anual de 3.540,7 pesos de oro. En términos comparativos, la recaudación por este concepto en Santiago ascendía a 30.658 pesos con un promedio de 4.379,7 pesos anuales; mientras en Valdivia desde 1554 a 1558 el arriendo del impuesto fue de 12.650 pesos, con un promedio anual de 3.162 pesos $^{52}$. Los datos presentados corroboran la significación de la agroganadería en la Gobernación de Chile y en la ciudad de Imperial.

45 Proceso de Francisco de Villagra II. Declaraciones prestadas en la Imperial, al tenor del mismo interrogatorio de Francisco de Villagra, insertándose primeramente, la provisión real de la Audiencia de Lima y el interrogatorio del acusado. Imperial, 15-IX-1558. CDIHCh, tomo 21, p. 517.

46 Proceso de Villagra III. Actuaciones hechas en la ciudad de Santiago. Declaración de Cristóbal Rodríguez de Imperial. Santiago, 1558. CDIHCh, tomo 22, pp. 410-411.

47 Proceso de Villagra I. Información hecha por el fiscal Juan Pérez Teruel para acreditar los delitos y agravios que Francisco de Villagra hizo en esta gobernación, especialmente después que murió don Pedro de Valdivia, Gobernador que fue de ella. Concepción, 12-XI-1558. CDIHCh, tomo 20, p. 353.

48 Proceso de Villagra III. Actuaciones hechas en la ciudad de Santiago. Declaración de Juan Bautista Matusano de Santiago. Santiago, 1558. CDIHCh, tomo 22, p. 383. Respecto del peso de la fanega se observan diferencias entre la "fanega castellana" de 55,55 litros equivalente a 45,6 kilos, utilizada en el siglo XVI ver Río - LóPez y SEBASTIÁn, 1996, p. 37; y la fanega de 6 arrobas o 150 libras utilizada en el siglo XVII y XVIII, ver De Ramón - Larraín, 1982, p. 47; Schlupmann, 2006, p. 89; Carmagnani, 2001, p. 75.

49 Proceso de Villagra III. CDIHCh, tomo 22, p. 428.

50 Ibídem, p. 616.

51 Cuenta de lo que importa el diezmo en el reino de Chile 1546-1558. Santiago, 1558. CDIHCh, tomo 13, p. 480.

52 Ibídem, p. 480. 
En un documento que reseñaba la situación del corregimiento en la década de 1590 se describía el notable desarrollo combinado de las actividades agroganaderas y mineras a fines del siglo XVI:

La ciudad Imperial era frontera que dividía la guerra de Purén Arauco y Tucapel, Catiray y la cordillera de las ciudades de arriba y a toda esta guerra hacía frente con cuatro fuertes que tenía en la ribera del Cautén y otros tres hacia la cordillera y cabezadas de la ciudad Imperial y Ciudad Rica, y con esto se hacía la guerra al enemigo: es puerto que sin él no podrán tener paz las ciudades de arriba. Hacía guerra a sus términos que son Tirúa, Calcayuso, Rolomo, Duca-Duca, Payllaguen, Virquen, Caypio y Calbillaga y Puello y cabezadas de la dicha ciudad Rica y toda la cordillera hasta los términos de Angol, fertilísima de pan y carne y algún vino y muchos pastos y riquísima de oro; tenía más de 20 a 30 mil cabezas de ganados y en sus contorno había más de 3.000 caballos y tenía indios de paz 2.000 para arriba, muy bien poblada de casas de teja $^{53}$.

La organización de las haciendas y estancias españolas creaba un paisaje de suyo exuberante en la Araucanía del siglo XVI, por ello la comarca de la Imperial podía ser descrita como "fertilísima de pan y carne y vino y mucho pasto y riquísima de oro", y su centro urbano como una ciudad "muy bien poblada de casas de tejas", signos inequívocos del arraigo y prosperidad de la colonización en el corregimiento costero de Imperial.

\section{COMERCIO, TRÁFICO TERRESTRE Y MARÍTIMO INTERCOLONIAL}

Respecto a las vías de comunicación de la Ciudad Imperial con la Gobernación y el Virreinato, el estuario del río Cautín se consideraba una buena alternativa de navegación fluvial para salir al mar abierto. No obstante, la existencia de bancos de arena en su desembocadura y la ausencia de una bahía protegida contra los fuertes vientos del Oeste, creaban un escenario peligroso para la navegación de embarcaciones mayores, por lo cual sólo se utilizaban embarcaciones pequeñas, de cabotaje costero. El cronista Antonio de Herrera, ampliaba estas referencias sobre los problemas de la navegación fluvial señalando: "Entran barcas por el río hasta la ciudad, y no tiene puerto, por ser playa con bancos de arena de a tres brazas, y a dos y media ${ }^{54}$. Los bancos de la desembocadura del río Cautín limitaban las potencialidades de navegación fluvial, situación que indujo el aprovechamiento del puerto meridional de la ciudad de Valdivia, para el embarque de la producción local y la recepción de tropas, pertrechos y mercaderías. En el título de encomienda de Jerónimo de Alderete se especificaba claramente la temprana conexión mercantil establecida entre el distrito de Imperial y el puerto de Valdivia, a través de la asignación de una estancia para crianzas de animales

53 Pareceres que tenía Alonso de Ribera cuando llegó a Chile para el buen acierto en la guerra y gobierno

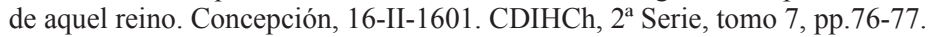

54 Herrera, 1730 , p. 157. 
de tiro y arrías de transporte y de un grupo de indígenas de encomienda para realizar el servicio de las comunicaciones. En este importante documento se estipulaba:

y porque en la ciudad de Valdivia hay buen puerto os encomiendo allí, para que podáis tener una estancia, los principales dichos Navultureo, Chaite, Huechin e Ingaiguano, con cien indios de visitación para que os sirváis de todos ellos conforme a los mandamientos e ordenanzas reales, dejando a los caciques principales sus mujeres e hijos e los otros indios de su servicio ${ }^{55}$.

El pingüe negocio de la guerra de conquista y la explotación de minerales preciosos, constituía un giro mercantil de extraordinario estímulo a las actividades productivas de las ciudades del Sur a través de la conexión comercial con la gobernación y el virreinato. En este sentido es útil recordar que después de la fundación de Concepción, Jerónimo de Alderete tesorero de la Real Hacienda y Esteban de Sosa Gómez contador de la misma, suscribieron una sociedad para adquirir una embarcación en Lima y dedicarla al transporte marítimo. Según indicaba el contrato suscrito ambos socios aportaban 2.500 pesos de oro, en tanto Esteban de Sosa debería viajar a Lima, para traer la nave cargada de mercaderías a Valparaíso y Concepción ${ }^{56}$.

La conexión mercantil marítima de las ciudades del Sur con el virreinato tendrá un carácter permanente durante el siglo XVI, sobre todo porque Lima era el centro proveedor de pertrechos bélicos y soldados, así como de las mercaderías europeas apetecidas por la nobleza de encomenderos, comerciantes y militares de Chile. En este sentido, se apuntaba que en el socorro traído por García Hurtado de Mendoza para la guerra de Arauco, el gobernador trajo: "una cargazón de mercaderías de 20.000 ducados de empleo de Castilla, por la cual le daban en esta (Lima) 35.000 pesos y valía en Chile casi 50.000 en oro" 57 . Estos bienes fueron proveídos a los vecinos-soldados de Imperial que vinieron a recibirle a Concepción ${ }^{58}$.

La ciudad de Valdivia con su inmejorable puerto fluvial sobre el río Callecalle conformaba un enclave comunicacional de enlace hacia Concepción, Valparaíso y Lima, como punto de entrada y salida del oro producido en Villarrica e Imperial, según observaba el cronista Bibar ${ }^{59}$. De esta manera el puerto de Valdivia tenía una conexión directa con el comercio virreinal. En este sentido, hacia fines del siglo, se apuntaba que el gobernador Oñez de Loyola tuvo negocios de importancia en su venida a Chile desde Perú. Un viajero español que visitaba la región el año 1600, manifestaba:

Este desdichado Gobernador que era más mercader que soldado había ido a la ciudad de Valdivia personalmente a cobrar cierto oro que le debían de mercadería que

\footnotetext{
55 Juan Godinez, vecino de Chile, con doña Esperanza de Rueda y Pedro de Miranda, de la misma vecindad, sobre ciertos indios. Título de encomienda a Jerónimo de Alderete. Valdivia, 4-III-1552. CDIHCh, tomo 14, pp. 222-223.

56 Hernando de Huelva, vecino de Chile, cesionario de Jerónimo de Alderete, con el capitán de Esteban de Sosa, sobre ciertas cuantías de maravedises. Santiago, 28-X-1550. CDIHCh, tomo 9, p. 120-121.

57 Probanza de los méritos y servicios de don García de Mendoza y Manrique. Los Reyes, 7-V-1561. CDIHCh, tomo 27, p. 18.

58 Ibídem, p. 18.

59 BiBAR, 1966, p. 141.
} 
tenía allá y también levantar y apercibir gente para la guerra, y volviendo a la ciudad de Angol, donde se junta el ejército para entra en la guerra, adelantose con 50 hombres y viniendo de la Imperial para Angol hizo dormida y alójose en un río llamado Curalava $^{60}$.

La historiografía chilena en un sugerente enfoque sobre la actividad mercantil en el siglo XVI muestra un activo mercado colonial que funciona en tres niveles, local, regional y extrarregional, basado en el intercambio de productos primarios por las mercaderías virreinales. Sin duda que el oro constituía el principal reglón de los intercambios de Chile en estas décadas, no obstante el trigo producido en la Gobernación también era un producto atractivo para la creciente demanda de alimentos en el espacio limeño donde se enviaba ya en 1590 junto a los productos ganaderos de sebo y charqui ${ }^{61}$. La importancia del comercio colonial basado en el conjunto de actividades minero-agrícolas, contribuyó para que la ciudad Imperial alcanzara un notable grado de desarrollo urbano en ámbito virreinal. Hacia 1575 contaba con 170 vecinos, situándose en el tercer lugar de los centros urbanos de Chile, después de Santiago y Valdivia. Además, las ciudades del Sur de la Gobernación no llevaron una existencia precaria como podría suponerse por la presencia de un conflicto indígena abierto y latente. Por el contrario, estos asientos urbanos contaban con todos los servicios para llevar una vida próspera, igual que las otras ciudades de rango equivalente en América hispana. Asimismo, durante el siglo XVI se considera que la región más rica y desarrollada del territorio chileno era la zona del Obispado de Imperial, que incluía las ciudades de Concepción, Chillán, Angol, Valdivia, Villarrica, Osorno, Castro, y la ciudad homónima, sede del episcopado ${ }^{62}$.

\section{LA POBLACIÓN INDÍGENA DEL CORREGIMIENTO}

La población indígena conformó una fuente de recursos laborales de extraordinaria importancia para el desenvolvimiento de las explotaciones económicas españolas. Asimismo, el volumen de la población indígena repartida en encomiendas es un factor directamente relacionado con el monto de la producción de bienes agropecuarios y mineros generados en el distrito colonial. Mayor número de brazos implicaba mayor volumen de atesoramiento de riquezas para el consumo y el comercio.

El cronista Mariño de Lobera, soldado de la etapa inicial de la conquista del Sur de Chile, respecto del número de la población mapuche en la comarca del río Cautín escribió: "Esta es la disposición de esta tierra; la cual tendrá ocho leguas de distrito, en la cual habrá pasados de 800.000 indios casados, ultra de los solteros que eran sin número"63. En otro acápite indicó "haber hallado cuando entraron los españoles pasados de 1.500 en este distrito" "64. Diego de Rosales, a mediados del siglo XVII

\footnotetext{
60 OCAÑA, 1995, p. 43.

61 Villalobos, 1983; Assadourian, 1983; Pinto 2000; Carmagnani, 2001; Cavieres, 2003.

62 Guarda, 1978, p. 24.

63 LoberA, 1861, p. 125.

64 Ibídem, p. 330.
} 
consigna un número de 300.000 indios para esta misma zona siguiendo los registros de la ciudad ${ }^{65}$. Estos números entregan una aproximación global sobre el volumen demográfico de la población laboral. No obstante, los datos aportados en probanzas y relaciones de méritos y servicios, permiten aproximarnos al cálculo de la población indígena del siglo XVI desde una perspectiva comparativa con los datos entregados por los cronistas.

Un vecino español de la ciudad Imperial declaró que Pedro de Valdivia viendo la multitud de naturales de la comarca: "fizo e nombró muchos vecinos, dándole espléndidos repartimientos, por haber en la comarca de 20 leguas más de 150.000 indios" ${ }^{66}$.

Respecto de la cifra de tributarios localizados sólo entre el río Cautín y el Toltén, en una probanza del vecino Pedro Olmos de Aguilera se apuntaba que: "conquistó, allanó y trajo de paz mas de 50.000 indios que estaban poblados entre los ríos Toltén e Cautén" ${ }^{67}$. El cabildo de Angol escribía al rey en 1563 sobre los servicios de Pedro de Villagrán, observando que su diligencia la: "mostró bien en la ciudad Imperial, donde se halló, con más de 80.000 indios en sus términos alzados" 68 .

Las cifras parciales de 50.000 y 80.000 junto al número global de 150.000 indios, tienen correspondencia con los datos referidos al número de tributarios entregados en encomienda. Contrastaremos estos cómputos globales con las cifras del número de tributarios encomendados a los vecinos de la ciudad. Mariño de Lobera entrega el siguiente cuadro de algunas encomiendas asignadas por Pedro de Valdivia en Imperial: a Francisco de Villagra 30.000 en la comarca de Maquehua; Jerónimo de Alderete 12.000 en Toltén Bajo; Andrés Hernández de Córdova 6.000, sin indicar lugar, y Pedro Olmos de Aguilera 12.000 en Budi; Pedro de Villagrán 15.000 en Tirúa; y Pedro de Valdivia con 30.000 en Pucureo ${ }^{69}$. El cronista Carvallo utilizando otros registros apuntaba adicionalmente las encomiendas entregadas a Diego Martín Ballestero con 1.000; Luis Barba con 1.500 y Hernando de San Martín con 800 ${ }^{70}$. Estos nueve encomenderos reúnen 78.300 tributarios. A ellos sumaremos las encomiendas de Gaspar de Orense con 6.000 y Antonio Tarabajano con 3.000 tributarios, citadas anteriormente. Asciende la estadística total de 11 encomenderos a 117.300 tributarios en el corregimiento de Imperial. Este número representa una parte significativa del conjunto total de tributarios, no obstante que el registro de encomiendas no es completo.

Otro tipo de clasificación de la población laboral indígena consigna la figura de "casas de visitación". Francisco Villagra refería en un documento el tamaño de su enco-

65 Rosales, 1989, tomo I, p. 401.

66 Probanza de méritos y servicios de Juan Beltrán de Magaña en la batalla de Xaquijaguana contra Gonzalo Pizarro y después en Chile con el Gobernador Valdivia, conquistando y poblando aquel reino, especialmente la ciudad de la Concepción y otras. Santiago, 19-VI-1563. CDIHCh, tomo 16, p. 389.

67 Los servicios que el capitán Pedro Olmos de Aguilera, vecino de la ciudad Imperial, ha hecho a Su Majestad después que partió de los reinos de España a esta parte de Indias son los siguientes. Concepción, 24-VII-1574. CDIHCh, tomo 25, p. 31.

68 Carta del cabildo de la ciudad de los Confines al rey. Los Confines, 3-XI-1563. CDIHCh, tomo 30, p. 142.

69 LOBERA, 1861, pp. 142, 144, 297.

70 Carvallo, ca. 1875, tomo 9, nota 56. También ver Rosales, 1989, tomo I, p. 401. 
mienda, señalando "que todos pueden ser cantidad de 10.000 indios de visitación" A Martín Villareal se entregaba un repartimiento "con 470 casas de visitación" Mientras en la cédula de Jerónimo de Alderete se consignó la entrega de una encomienda: "con 388 casas que parescen tener de visitación, y todos estos lebos, cabíes, o reguas dichos, con estos principales, se [os] dan con 6.000 indios de visitación ${ }^{73}$. La clasificación de casas de visitación e indios de visitación posibilita realizar cálculos demográficos proyectivos. En la encomienda de Alderete el número de casas es de 388 , dividido por el número de 6.000 indios tributarios da un promedio superior a 15 tributarios por casa de visitación ${ }^{74}$.

En este escenario inicial, la cifra de 150.000 tributarios constituye un rango plausible del número de hombres adultos en el distrito de la ciudad. Su proyección demográfica según el índice de cinco personas por tributario alcanzaría a 750.000 habitantes para mediados del siglo XVI. Este cálculo corrobora las metodologías que proponen altos rangos de población indígena en el Sur de Chile en el momento del choque con el conquistador, con cifras superiores al 1.500.000 ó 2.000.000 de habitantes. En contraste con las propuestas de cifras mínimas, aunque relevantes, cercanas a los 600.000 pobladores a mediados del siglo $\mathrm{XVI}^{75}$.

La magnitud de la población indígena regional fue un factor de extraordinaria importancia como fuente de mano de obra para el desarrollo de una próspera economía, basada en el trabajo masivo en faenas mineras, producción agrícola y transporte de bienes.

\section{CONCLUSIONES}

Desde un punto de vista espacial, la fundación española en el río Cautín tendrá una función estratégica para conquistar y colonizar el territorio comprendido desde el río Malleco al río Callecalle, a través de la inter-conexión de las ciudades de Imperial, Angol, Villarrica y Valdivia, teniendo como centro administrativo la ciudad Imperial, residencia de los primeros Gobernadores y conquistadores y sede del segundo Obispado de la Gobernación. Por otro lado, el corregimiento de Imperial controló uno de los centros demográficos indígenas de mayor tamaño y desarrollo económico prehispánico en el Sur de Chile. Esta circunstancia permitió a los europeos explotar los recursos económicos locales mediante el trabajo masivo de la población de las

\footnotetext{
71 Información rendida en Santiago por Francisco de Villagra, para acreditar la necesidad que tenía de dinero para comprar caballos, armas y otras cosas a fin de ir al socorro de las ciudades del sur. Santiago, 6-X1554. CDIHCh, tomo 20, p. 292.

72 Encomienda de Pedro de Valdivia a favor de Pedro Martín de Villarreal. Valdivia, 4-III-1552. CDIHCh, tomo 9, p.411, también citado por BENGOA, 2003, p. 167.

73 Juan Godinez, vecino de Chile, con doña Esperanza de Rueda y Pedro de Miranda, de la misma vecindad, sobre ciertos indios. Santiago, 30-XII-1564. CDIHCh, tomo 14, p. 222-223.

74 Nuestra metodología difiere de las propuestas de Villalobos, 1983, tomo 1, p. 95, nota n 30, acerca de la clasificación de los "indios de visitación" como población que incluye mujeres, niños y ancianos. También diferimos del índice de seis personas por “casas de visitación”, propuesto por BENGOA, 2003, pp. 167 y 169.

75 En el primer caso Hidalgo, 1973, p. 42; BengoA, 2003, p. 158; en el segundo Villalobos 1983, tomo 2, pp. 94-95; TÉLleZ, 2004.
} 
encomiendas en la minería, en el cultivo del trigo y en crianzas ganaderas, generando una extraordinaria riqueza de oro y abundantes excedentes agropecuarios para el abasto local, el consumo de las guarniciones y el comercio intercolonial. En este sentido es relevante la conexión marítima de Imperial con el puerto de Valdivia, como vía de articulación de las economías regionales del Pacífico Sudamericano al centro mercantil de Lima; esquema comercial presente desde el inicio de la expansión colonizadora iniciada con Pedro de Valdivia y la fundación de la Imperial en 1551, que se mantendrá lo largo del siglo XVI.

A fines de la década de 1590 las ciudades de Araucanía, fueron asediadas y destruidas simultáneamente por las huestes mapuche, que habían incorporado los caballos y las armas de hierro introducidos por los europeos. Valdivia y Villarica fueron arrasadas, mientras las ciudades de Imperial y Angol eran abandonadas en abril de 1600. Osorno fue desalojada en 1604; sólo subsistirían las ciudades de Concepción y Castro en el Sur de Chile. A partir de ese momento, se establece la frontera hispano-mapuche del río Biobío, donde observaremos la continuidad de las interrelaciones económicas generadas en las ciudades del siglo XVI, a través del comercio fronterizo de bienes recibidos desde Lima en el puerto de Concepción, para obtener en retorno desde Araucanía equinos, vacunos y tejido de lana; además de mano de obra indígena libre como mitayos y peones de alquiler de la comarca de Imperial, que se trasladan a trabajar en la producción triguera de las haciendas de Concepción para el mercado limeño.

\section{REFERENCIAS BIIBLIOGRAFICAS}

Adán A. Leonor - Mera M. Rodrigo

2010 "Variabilidad interna en el alfarero temprano del Centro Sur de Chile: el complejo pitrén en el valle central del Cautín y el sector lacustre andino". Chungará. Arica, vol. 43 , pp. 3-23.

Assadourian, Carlos Sempat

1983 El sistema de la economía colonial. Mercado Interior. Regiones y espacio económico. México. Editorial Nueva Imagen.

Barros Arana, Diego

1873 Proceso de Pedro de Valdivia y otros documentos concernientes a este conquistador. Santiago de Chile. Imprenta Nacional.

Barros Franco, José Miguel

1991-1992 "Rey don Felipe. Plano de una fundación urbana en el Estrecho de Magallanes". Boletín de la Academia Chilena de la Historia. Santiago de Chile, nº 102, pp. 387-401.

BengOA, José

2003 Historia de los antiguos mapuche del Sur de Chile. Santiago de Chile. Editorial Catalonia.

BIBAR, Jerónimo de

1966 Crónica y relación copiosa de la conquista de los reinos de Chile [1558]. Santiago de Chile. Editorial Universitaria.

CÁceres GonzÁlez, Osvaldo

1991 "Las ciudades fundadas por Pedro de Valdivia". En Rojas Mix, Cartas de Don Pedro de Valdivia. Barcelona. Lumen, pp. 225-229. 
Campos Harriet, Fernando

1979 Historia de Concepción 1550-1970. Santiago de Chile. Editorial Universitaria.

CAMPBel, Roberto

2008 “El trabajo de metales en la Araucanía (siglos X-XVII D.C.)”. En AustraL - TAmagniNI, Problemáticas de la Arqueología Contemporánea. Río Cuarto. Universidad Nacional de Río Cuarto, tomo II, pp. 501-510.

CARMAGnANi, Marcello

2001 Los mecanismos de la vida económica en una sociedad colonial. Chile 1680-1830.

[1973]. Santiago de Chile. Dibam.

Carvallo y Goyeneche, Vicente

1875-1876 Descripción histórico geográfica del reino de Chile. [1796]. Colección de Historiadores de Chile y de documentos relativos a la historia nacional (CHCh). Santiago de Chile. Imprenta El Ferrocarril, tomos 8, 9 y 10.

Cavieres F., Eduardo

2003 Servir al soberano sin detrimento del vasallo. Valparaíso. Ediciones Universidad Católica de Valparaíso, pp. 23-62.

COLECCIÓN

1888-1903 Colección de documentos inéditos relativos a la historia nacional. Santiago de Chile. Imprenta Elzeviriana. 30 tomos.

1956 Colección de documentos inéditos relativos a la historia nacional. Segunda Serie. Santiago de Chile. Fondo Histórico y Bibliográfico José Toribio Medina. 7 tomos.

Cuesta Domingo, Mariano

2007 "Los cronistas oficiales de Indias. De López de Velasco a Céspedes del Castillo". Revista Complutense de Historia de América. Madrid, vol. 33, pp. 115-150.

Dillehay, Tom

2011 Monumentos, imperios y resistencia en los Andes. El sistema de gobierno mapuche y las narrativas rituales. Santiago de Chile. Ocho libros Editores.

DE RAMÓN, Armando

2000 Historia de Santiago 1541-1991. Historia de una sociedad urbana. Santiago de Chile. Editorial Sudamericana.

De Ramón, Armando - Larraín, José Manuel

1982 Orígenes de la vida económica chilena 1659-1808. Santiago de Chile. Centro de Estudios Públicos.

GóngORA, Mario

1970 Encomenderos y estancieros: estudios acerca de la constitución social aristocrática de Chile después de la conquista, 1580-1660. Santiago de Chile. Editorial Universitaria.

GuARDA, Gabriel, OSB

1978 Historia urbana del reyno de Chile. Santiago de Chile. Editorial Andrés Bello.

1990 Flandes indiano: las fortificaciones del reino de Chile, 1541-1826. Santiago de Chile. Ediciones de la Universidad Católica de Chile.

1993 Una ciudad chilena del siglo XVI: Valdivia, 1552-1604, urbanística, res pública, economía, sociedad. Santiago de Chile. Ediciones de la Universidad Católica de Chile.

HERRERA, Antonio

1730 Historia general de los hechos de los castellanos en las islas y Tierra Firme del Mar océano. [1601-1615]. Década octava al Rey Nuestro Señor. Madrid. Imprenta Real Juan Flamenco. 
HidALGO L., Jorge

1973 Algunas notas sobre los mapuche protohistóricos. Temuco. CUHSO.

InOSTROZa CoRdova, Iván

1992 "Los mitayos araucanos y los indios penquistas 1600-1620". Revista de Historia. Concepción, vol. 2, pp.129-146.

1998 Historia de Concepción. Organización colonial y economía agraria, 1600-1650. Temuco. Ediciones de la Universidad de la Frontera.

2010 "La civilización agrominera y comercial mapuche, siglo XVI". Andes del Sur. Temuco, no 1, pp. 20-55.

LEÓN Solís, Leonardo

1991 La merma de la sociedad indígena de Chile central y la última guerra promancae, 1541-1558. St. Andrews. Institute of Amerindians Studies.

LoBera, Pedro Mariño de

1861 Crónica del Reino de Chile. [1592]. En Colección de Historiadores de Chile y de documentos relativos a la historia nacional (CHCh). Santiago de Chile. Imprenta del Ferrocarril, tomo VI.

LÓPEZ de Velasco, Juan

1894 Geografía y descripción universal de las Indias recopiladas por cosmógrafo-cronista Juan López de Velasco desde el año de 1571 al de 1574. ZARAGOZA (ed.). Madrid. Boletín de la Sociedad Geográfica de Madrid. Establecimientos Tipográficos de Fortanet.

López y Sebastián, Lorenzo E. - Río Moreno, Justo L.

1993 "Trigo y poblamiento en la Española durante la segunda mitad del siglo XVI". Revista Complutense de Historia de América. Madrid, vol. 19, pp. 53-80.

MARTINIC, Mateo

1983 "El Reino de Jesús. La efímera historia de una gobernación en el Estrecho de Magallanes". Anales del Instituto de la Patagonia. Punta Arenas, nº14, pp.7-32.

Millán, Augusto

2001 Historia de la minería del oro en Chile. Santiago de Chile. Editorial Universitaria.

MuÑoz CoRreA, Juan Guillermo

1989 Pobladores de Chile, 1565-1580. Temuco. Ediciones Universidad de la Frontera.

1992 "Antecedentes de la actividad agroganadera entre 1565 y 1580 en las cuentas de la Real Hacienda”. En MuÑoz - Orellana, El agro colonial. Santiago de Chile. Ediciones de la Universidad de Santiago.

MuÑoz C., Juan Guillermo - Orellana M., Marcela

1992 El agro colonial. Santiago de Chile. Ediciones de la Universidad de Santiago.

OCAÑA, Fray Diego

1995 Relación del viaje a Chile, año 1600, contenida en la crónica de viaje intitulada "A través de la América del Sur”. Prólogo de Lorena Loyola GoIC. Introducción y notas Eugenio Pereira Salas. Santiago de Chile. Editorial Universitaria.

Olivares, Miguel de

1864 Historia militar, civil y sagrada del reino de Chile. [1738]. Colección de historiadores de Chile y de documentos relativos a la historia nacional (CHCh), tomo IV. Santiago de Chile. Imprenta del Ferrocarril. 
PinTo R., Jorge

2003 La formación del Estado y la nación, y el pueblo mapuche: de la inclusión a la exclusión. Santiago de Chile. Dirección de Bibliotecas, Archivos y Museos - Centro de Investigaciones Diego Barros Arana.

Porras Barrenechea, Raúl

1999 “Oro y leyenda en el Perú”. En Porras Barrenechea, El legado quechua. Lima. UNMSM Fondo Editorial.

Ramos, Demetrio

1967 Trigo chileno, navieros del Callao y hacendados limeños entre la crisis agrícola del siglo XVII y la comercial de la primera mitad del siglo XVIII. Madrid. Ediciones CSIC - IGFO.

Río Moreno, Justo L. - LóPez y Sebastián, Lorenzo E.

1996 "El trigo en la ciudad de México. Industria y comercio de un cultivo importado (15211564)". Revista Complutense de Historia de América. Madrid, vol. 22, pp. 33-51.

Rojas Mix, Miguel - Podestá, Mario Ferreccio (eds)

1991 Cartas de Don Pedro de Valdivia: que tratan del descubrimiento y conquista de la Nueva Extremadura. Prólogo e iconografía de Miguel Rojas Mix; transcripción y notas de Mario Ferreccio Podestá. Barcelona. Lumen.

Rosales, Diego de

1989 Historia General del reino de Chile, Flandes indiano. [1674]. Santiago de Chile. Editorial Andrés Bello. 3 tomos.

SCHLÜPMANN, Jakob

2006 Cartas edificantes sobre el comercio y la navegación entre Perú y Chile a comienzos del siglo XVIII. Correspondencia y contabilidad de una compañia comercial, 17131730. Lima. Talleres Gráficos Tarea - Asociación Gráfica Educativa.

SLicher Van Bath, Bernard

1979 "Economic Diversification in Spanish America around 1600: Centres, Intermedies Zones and Peripheries". Jarbuch für Geschichte Lateinamerikas. Köln/Weimar/Wien: Böhlau Verlag, vol. 16. pp. 53-95.

Solano, Francisco de

1996 "La expansión urbana ibérica por América. Una consecuencia de los tratados de Tordesillas". Revista de Indias. Madrid, vol. LVI, n 208, pp. 615-636.

TÉLLEZ L., Eduardo

2004 "Evolución de la población mapuche del Reyno de Chile". Historia Indígena. Santiago de Chile, $n^{\circ} 8$, pp.101-126.

VALENZUELA, M. Jaime

2010 "Indígenas andinos en Chile colonial: inmigración, inserción espacial, integración económica y movilidad social (Santiago, siglos XVI-XVII)”. Revista de Indias. Madrid, vol. LXX, n 250, pp. 749-778.

Villalobos, R., Sergio

1983 Historia del pueblo chileno. Santiago de Chile. Editorial Zig-Zag, tomos 1 y 2. 